\title{
The Life Long Learning Policy in Greece under Deliberation: Aspects of a Formal Exchange of Views
}

\author{
Olga Chaitidou \\ University of Western Macedonia, Greece \\ E-mail: ohaitidou@uowm.gr \\ Evagelia Kalerante \\ University of Western Macedonia, Greece \\ E-mail: ekalerante@yahoo.gr
}

Argyris Kyridis

Aristotle University of Thessaloniki, Greece

E-mail: akiridis@nured.auth.gr

Christos Zagkos (Corresponding author)

Centre for Educational Policy Development (KANEP/GSEE), Greece

E-mail: chzagkos@kanep-gsee.gr; zagbal2003@yahoo.gr

Nikos Fotopoulos

University of Western Macedonia, Greece

E-mail: nfotopoulos@uowm.gr

Received: April 25, 2013 Accepted: May 23, 2013 Published: July 2, 2013

doi:10.5296/ire.v1i1.3567 URL: http://dx.doi.org/10.5296/ire.v1i1.3567 


\section{Abstract}

The present paper is involved with Lifelong Education in Greece as a means to provide broader population strata skills and abilities enabling them to easier integrate into the labor market within an economic crisis period. The specific educational policy had been under public deliberation on the Internet so that its implementation could be based on the opinions generated by the citizens' society and not merely on parliamentary voting. A total of 8 carriers and 49 individuals participated in the deliberation procedure while their views, standpoints and suggestions were thoroughly investigated on the basis of five thematic units, namely Lifelong Education definition, objectives, perspectives, critique by the citizens and personal benefits and having taken into consideration a broader social demand to further knowledge and qualifications. Thus, the issue of Lifelong Education is tied to the knowledge society and innovation targeting at the educational systems efficiency and effectiveness and, simultaneously, combating the insecurity and uncertainty generated by the socio-economic developments and experienced by the lower social strata and women within a changing and developing society. Besides, a wide reservation among interviewees towards the decentralized authorities in terms of implementing the new policy is made evident by the research findings and their analysis.

Keywords: citizens' society, deliberation, effectiveness, efficiency, innovation, knowledge, lifelong

\section{Introduction}

The systematic promotion of the investment policy in the human capital has been evident in the European Union since 2000. This theoretical framework is associated with Lifelong Education concentrating on a model of knowledge provision and training of broader population strata. Educational systems competitiveness and efficiency is tied to the broader draft of harmonization of economy and education. In the Lisbon and Barcelona (Dehmel, 2006) Meetings, strategies about the reforms of the educational systems aiming at the improvement of quality and effectiveness (Preece, 2011) were developed. The society of knowledge was schematically defined (Raju, 2010; Al-Hawamdeh \& Hart, 2001), namely a standardized knowledge focusing on economic objectives while the humanistic dimensions that would eventually change the educational environment of the European Union countries was overlooked (Riddell, Markowitch, \& Weedon, 2012).

An open dialogue system with the local society was introduced by the G. Papandreou Government so that public sector reformation issues or reforms were promoted. A channel of communication about issues related to voting laws deemed to be integrated into the innovative views about Education or Administration was introduced. Deliberation was considered to be innovative for the Greek political system as the submission of a draft in the parliament and its voting or rejection by the parliament members was foreseen for the change in the policy or the institution of laws.

The issue of deliberation is related to the more general government intentions for the citizens' society function within the framework of internet society; that is, the citizens that would 
utilize the possibilities of technology conducive to the formulation of views and standpoints about political issues. The systematic implementation of deliberation by the Ministry of Education was observed following a model that foresaw: a) keynote questions and b) individual observations. Open questions were characteristically chosen so that argumentation would be provided by all citizens, carriers or pressure groups about the views formulated. The deliberation outcome was published on the internet and could theoretically function as political texts of consideration and dialogue.

Special emphasis was placed on Lifelong Learning by the Ministry of Education, an issue also associated with the addition of Lifelong Learning to its responsibilities and after which it has been called Ministry of Education, Lifelong Learning and Religion. In July 2010 the "Review of Law Draft Principles related to Lifelong Learning Development" was posed under public deliberation by the Ministry of Education. In particular, carriers and individuals were invited to present their views on the basis of the following questions. Views and suggestions for the particular deliberation were posed by 8 carriers and 49 individuals as it is shown by the publication of the deliberation.

(1) Which objectives, according to your opinion, should be pursued by the Lifelong Learning National Network?

(2) What do you suggest on the securing of the Lifelong Learning decentralization effectiveness across the Regions and Municipalities?

(3) What is your judgment on the administrative architecture of the Lifelong Learning system as it is foreseen by the draft law?

(4) How do you evaluate the Law Implementation Program prospect?

(5) What are, according to your opinion, the most significant incentives to develop Lifelong learning in our country?

(6) Which are, according to your opinion, the parameters that should be taken into account for the effective composition of the Lifelong Learning National Network evaluation and monitoring system?

(7) What are, according to your opinion, those elements that should be taken into account to evaluate an adult trainer's pedagogical proficiency?

In particular, deliberation on Lifelong Education seems to function on three levels. The education structures stand on the one level and the knowledge society stands on the other while the market economy stands on the third level. Deliberation is basically conducted so that suggestions about the association of these three levels are formulated.

\section{The Research}

Studying the deliberation of the Lifelong Learning Development Draft Law was considered as an exemplary study of the deliberation procedure in order to profoundly study both the deliberation planning procedure by the Ministry of Education and the content of answers provided by the individuals' having participated in the deliberation. 
The research objective is the investigation of suggestions, views and standpoints generated by the individuals - participants in the deliberation about the Lifelong Learning Development Draft Law. Since the LLL issue was particularly highlighted both by the European Union and the Greek government, the involvement with views provided by the individual citizens or carriers' representatives engaged in the deliberation policy was deemed interesting.

As it has also been mentioned, the deliberation points are expressed by seven open questions giving the possibility to compare views, suggestions and standpoints and, more general, to express negative or positive critique, an issue tied to the approval or disapproval either of lifelong education or its materialization procedure.

The researchers' sample consists of 8 carriers and 49 individuals participating in the deliberation by answering to questions. In the specific research, their views are evaluated as views of social and political subjects participating in an open democratic procedure. Even if their suggestions are not utilized or their observations are not eventually scrutinized by the Government, they are deemed active political people being engaged with the political discourse formulation.

In particular, through this sample, the elevation of Lifelong Learning objectives is pursued as it is perceived both by the individuals and carriers. At the same time, the Lifelong Learning Draft Law as well as its functional prerequisites is evaluated through their answers. Several elements are directly and indirectly collected as there are open questions. The individuals and carriers' views about the function both of the public and private sector as well as issues related to the political choices evaluation were investigated in the indirect elements as it is well-known that no evaluation culture has yet been formed within the Greek society.

\section{Methodology of the Research}

To study the answers provided both by individuals and carriers having participated in the internet deliberation, the content analysis method was used (Krippendorff, 2012). On a first level, in particular, the answers content for every carrier and individual was studied. On a second level, their answers were correlated to totally interpret the framework of ideas and standpoints of the parties involved in the deliberation (Schreier, 2012).

Regarding the analysis of the written statements of the subjects we used the methodological tool of Quantitative and Qualitative Content Analysis, which, as Curley (1990) states, allows (a) the combination of quantitative and qualitative data, (b) traces and recordes the types of social interaction through discourse analysis, (c) records historic and cultural elements, (d) records and analyzes social ideologies and (e) investigates concepts as well as the ways in which the specific concepts are perceived by social subjects. In detail, the texts were analyzed following the principles of Quantitative Content Analysis, as they were stated by Holsti (1969), Berelson (1971), De Sola Pool (1959), Palmquist (1990), Weber (1990) and by French researchers (Moscovici, 1970; Mucchielli, 1988; Veron, 1981; Bardin, 1977; Grawitz, 1981) (classical thematic analysis). The "theme" was considered as the basic unit of analysis (Lasswell, Lerner, \& Sola Pool., 1952; Lasswell \& Leites, 1965). 
The research findings were utilized in a dual qualitative analysis approach in which emphasis was placed on the content conceptualization. Concentration was not placed on the quantitative analysis with emphasis on measurable data (Leetaru, 2011) such as the frequency of words or sentences referring to quoting or reiterating specific views because such a thing in the particular research was considered fragmentary for the notional unity and ideological schemata projection.

To sum up, the carriers and citizens' comments or views having been integrated into sets and subsets were used as an analysis unit soon after the indexing from the Ministry of Education website. A correlation followed with more specific data about the involved ones' gender, professional relationship, their educational capital and, in the case of carriers, their involvement with the Lifelong Education procedure.

A combining method with different variables was evaluated to more systematically project the involved parties' views and to improve their interpretational perspective in order to approach more effectively the content of answers and eventually the overall investigation about deliberation regarding Lifelong Learning (Creswell, 2008).

\section{Results of the Research}

\subsection{Quantitative Analysis of the Data}

In order to elevate the differentiation of views among the individuals, carriers and collectivities, their answers were analyzed in the seven aforementioned questions on the basis of the thematic units: a) Lifelong Education definition, b) Objectives, c) Lifelong Education perspective, d) Carriers' critique and e) personal benefit conceptualization. The Lifelong Education definition refers to question one, objectives cover questions five and six, the carriers' critique answer questions three and four and the Lifelong Education perspective does so in questions two and seven. For methodological reasons, since the research is a qualitative one, the individual's position in the system as the interviewee was determined, to elevate, therefore, the benefit definition from the Lifelong Education implementation under individual and social terms.

The individuals and carriers' concentration is placed on skills and training issues. Lifelong Education is regarded by unemployed people as a necessary step for their possible integration into the labor market. Lifelong Education is defined as a procedure of combining skills with special training for the labor market.

In the present research, the comments, the views of stakeholders and citizens were selected as a unit of analysis following the call of the Ministry of Education to public consultation on the draft Law on Lifelong Learning. The Public Consultation on the Draft Law consisted of seven main questions which formed the starting base of the Law for the Development of Lifelong Learning. 
Table 1. Distribution of the statements regarding the Ministry's questions

\begin{tabular}{|c|c|c|}
\hline Questions & Statements $(\mathbf{N})$ & $\%$ \\
\hline $\begin{array}{l}\text { 1. What objectives in your opinion should be pursued by the National Network of } \\
\text { LLL? }\end{array}$ & 233 & 36,7 \\
\hline $\begin{array}{l}\text { 2. What do you propose to ensure the effectiveness of decentralization of lifelong } \\
\text { learning to the Municipalities? }\end{array}$ & 60 & 9,4 \\
\hline $\begin{array}{l}\text { 3. What do you think about the administrative architecture of the lifelong } \\
\text { learning system? }\end{array}$ & 29 & 4,6 \\
\hline 4. How would you rate the Law for the Development of Lifelong Learning? & 13 & 2,0 \\
\hline $\begin{array}{l}\text { 5. What are in your opinion the most important incentives for the development of } \\
\text { lifelong learning in our country? }\end{array}$ & 63 & 9,9 \\
\hline $\begin{array}{l}\text { 6. What are in your opinion the parameters to be taken into account for the } \\
\text { effective establishment of the evaluation system and monitoring of the National } \\
\text { Network LLL? }\end{array}$ & 28 & 4,4 \\
\hline $\begin{array}{l}\text { 7. What are in your opinion the elements that should be taken into account when } \\
\text { evaluating the adequacy of a trainer of adults? }\end{array}$ & 209 & 32,9 \\
\hline Sum & 635 & 100 \\
\hline
\end{tabular}

Table 2. Thematic categories and distribution of the statements

\begin{tabular}{llll}
\hline & Thematic categories & $\mathbf{N}$ & $\mathbf{\%}$ \\
\hline $\mathbf{1}$ & Objectives of lifelong learning & $\mathbf{3 0 7}$ & $\mathbf{4 8 , 3}$ \\
1.1 & Education & 90 & 14,2 \\
1.1.1 & Primary / Secondary education & 11 & 7,1 \\
1.1 .2 & Adults Education & 32 & 20,5 \\
1.1.3 & Education of trainers & 22 & 14,1 \\
1.1.4 & Education vulnerable groups & 7 & 4,5 \\
1.1.5 & Vocational education & 4 & 2,6 \\
1.1.6 & Higher Education & 1 & 0,6 \\
1.1.7 & Informal Education & 5 & 3,2 \\
1.2 & Motivation for learning & 61 & 9,6 \\
1.2.1 & Material goods / services & 33 & 21,2 \\
1.3 & Connection of education with labor & 66 & 10,4 \\
1.4 & Needs of Greek society & 47 & 7,4 \\
1.4.1 & Vulnerable groups & 3 & 1,9 \\
1.4.2 & Economy & 4 & 2,6 \\
1.4.3 & Employment & 16 & 10,3 \\
1.5 & Decentralization & 24 & 3,8 \\
1.5.1 & Administrative decentralization & 7 & 4,5 \\
1.5.2 & Economic decentralization & 2 & 1,3 \\
1.6 & Flexibility / free access & 20 & 3,1 \\
\hline & & &
\end{tabular}




\begin{tabular}{llll}
\hline $\mathbf{2}$ & Expectations of the citizens & $\mathbf{1 7 2}$ & $\mathbf{2 7 , 1}$ \\
2.1 & Knowledge acquisition & 25 & 3,9 \\
2.2 & Certification & 29 & 4,6 \\
2.3 & Equality of opportunities & 19 & 2,8 \\
2.4 & Evaluation & 52 & 8,2 \\
2.4 .1 & Evaluation of educators & 5 & 3,2 \\
2.4 .2 & Evaluation of trainees & 1 & 0,6 \\
2.5 & Cooperation with institutions & 28 & 4,4 \\
2.6 & Connect theory with practice & 8 & 1,3 \\
2.7 & Developing entrepreneurship / innovation / social entrepreneurship & 11 & 1,7 \\
\hline $\mathbf{3}$ & Lifelong learning & $\mathbf{1 3 3}$ & $\mathbf{2 0 , 9}$ \\
3.1 & Experiential learning & 21 & 3,3 \\
3.2 & Green Development & 2 & 0,3 \\
3.3 & Operation of the Greek educational system & 15 & 2,4 \\
3.4 & Continuous supervision and regulation of the educational system & 5 & 0,8 \\
3.5 & Consulting & 17 & 2,7 \\
3.6 & Learning as a good & 7 & 1,1 \\
3.7 & Postgraduate studies & 24 & 3,8 \\
3.8 & Pedagogical adequacy & 42 & 6,6 \\
\hline $\mathbf{4}$ & Periphery \& Internationality & $\mathbf{2 3}$ & $\mathbf{3 , 6}$ \\
4.1 & Local Government & 4 & 0,6 \\
4.2 & European Union & 16 & 2,5 \\
4.3 & Social actors & 1 & 0,2 \\
4.4 & Organizations & 2 & 0,3 \\
\hline & & &
\end{tabular}

\subsection{Qualitative Analysis of the Data}

"Lifelong Learning forms a substantial opportunity for individuals to further their knowledge and skills and not any occasional clientele relationships".

More emphasis is placed on the association between Lifelong Education and the function of market by the public, but basically the private carriers, pinpointing, at the same time, under economic terms the notion of efficiency within a new "economic paradigm of efficiency and effectiveness" in which the Lifelong Education issue is tied to the knowledge society and innovation as an educational and economic objective during an economic crisis period. Benefit is defined under social and economic terms in which individual success is associated with collective utility.

On the basis of the specific framework, the carriers are observed to concentrate on the necessity of developing a constituted system reinforcing transparency in terms of qualifications through the promotion of a certification procedure so that there is a united evaluation framework.

"Transparency in the selection of educators and utilization of the excellent ones". "Securing of Lifelong Learning decentralization effectiveness. When all examination centers of an 
accredited carrier function in unity following the specifications and accredited procedures, the reliability of the certification procedure is secured irrelevant from the manner of their materialization".

Livelong Education is defined by the individuals under confining terms exclusively covering their benefit. Thus, Lifelong Learning is viewed by the teachers more as their training procedure in order to have a professional evolution and less in terms of improving their performance in their working environment. It is also pinpointed that the educational system is not functional whereas it is not believed that through the Lifelong Learning procedure there will be radical changes in the labor market and the educational carriers. It is believed that the system is multi-composed and that the terms of education and market function can not be redefined by Lifelong Education or training alone.

Lifelong Education is viewed by non educators and unemployed people as a procedure to increase their qualifications, the dysfunctions of the educational system are recognized and it is underlined that "opportunity structures" will be generated by Lifelong Education conducive to social mobility by restraining the insecurity and uncertainty experienced by the lower social strata. What is viewed through Lifelong Education is the possibility of being educated in foreign languages and computers by opening wide a discussion for professional outlets beyond the Nation State. Some individuals' view to acquire qualification through learning the language in order to work in Turkey or the Balkan countries is of special interest.

"In particular, the relationships between Greece and the Balkan countries will be in favor through the specialized syllabuses related to their object so that the Greeks' mobility, both the employed ones and scientists in the Balkans and Turkey, is in favor".

This is also an issue tied to the economic crisis and insecurity experienced so that Lifelong Education is regarded as a procedure of confronting their marginalization under economic and social terms as multiple social exclusions are marked by their non-entrance into the labor market. As it is mentioned:

"Education aims at the prevention of socio-economic developments, going along with and supporting them".

Carriers' representatives and individuals are observed to express their confidence to the carriers associated with education provision for integration into the labor market such as the Adults Education Centers (AEC) and the Employment Promotion Centers (EPC).

"The Adults Education Centers (AEC) contribution is deemed important, not to mention major, and in collaboration with the Municipalities, are by far conducive to Lifelong Learning. It is also desired to effectively contribute to the Certification of other education fields such as foreign languages and computers given the grounds that the material infrastructure and know-how are provided".

On the contrary, Municipalities are negatively evaluated through the questions posed about their effectiveness and, in general, the issue of Lifelong Education decentralization across Regions and Municipalities is addressed with reservation. The issue seems to be related to the 
lack of confidence towards political institutionalized carriers. The disapproval of decentralized structures or carriers is included in a broader political judgment in which political entities are disapproved.

"[...] Securing the effectiveness of Lifelong Learning decentralization in the Regions and Municipalities. Lifelong Learning should not form one more case of (STAGE), (NSRF) of subsidized programs etc. with a common thought in the Greek's mind: "snatching". The up today experiences have been proved non effective and non efficient (sic)".

The observations made in terms of gender are of special interest. During an economic crisis period, women feel insecure. It is underlined by the women of the sample that Lifelong Education will be conducive to acquiring "knowledge of usage" (Lewis, 2002; McMahon, 1995a; Mc Mahon, 1995b); that is, knowledge acquired in order to be used in the labor market (Hirata, 1988). They aim at the acquisition of foreign languages and computer knowledge, always based on an evaluation of the economic system needs.

A rational approach is formed in which theoretical knowledge, even university studies are demystified. Women are apparently ready to enter the labor market using any educational or technical capital and driven by the fear of unemployment as during an economic crisis period they are more threatened due to unemployment and find themselves in danger of marginalization.

"The aim is for the citizens to be provided the possibility of accessing education necessary to them as they have been provided limited or zero opportunities, e.g. a large number of clerks (mainly in the public sector) lacking the basic knowledge of computers. In jobs such as stitcher or seamstress, should the individuals be educated about modern machines, software included, they come back to the labor market. Of course, this is irrelevant to specialized scientific knowledge acquisition provided by universities. Thus, the aim is to keep in touch with technological developments, be able to implement them in one's field and acquire the basic ability to judge the consequences over the surrounding social environment, e.g. farmers".

The association between Lifelong Education and "The modernization of knowledge and skills and the apropos professional qualifications for all groups of employees" is underlined both by the individuals and carriers engaged with the technical works.

As regards unemployment, it is pinpointed that Lifelong Education will be conducive to "The promotion of employment through the human force's knowledge, skills and abilities development". Lifelong Education, associated with education or training of specialized personnel (Zito, 2001) is characteristically considered to function on the benefit of local societies.

Individuals of high educational capital are reserved towards the association of Lifelong Education with specialization and the single-sided association with labor by indirectly underlining that knowledge is related to thought and the formation of another type of man not necessarily confined to the exclusive acquisition of knowledge of usage. Individuals of a higher educational capital seem to be reserved towards training and specialization and 
without excluding the necessity for Lifelong Education in professional fields, the necessity of another kind of knowledge conducive to the development of human personality for the substantial contact with humanistic studies and for another content of knowledge conducive to the reformation of society is projected.

As regards deliberation on Lifelong Education, although the findings were published, no comments were generated by the Government and pressure groups.

\section{Discussion}

Even though special emphasis was placed on deliberation for Lifelong Learning, the carriers and individuals' involvement was exceptionally confined; and this is an issue related to the lack of real political dialogue within the Greek society. The Greeks have not yet been familiarized with open internet dialogue forms. More generally, there is a reservation towards the function of political institutions and probably the political subjects have no confidence towards the procedures.

The issue of Lifelong Education is integrated into the characteristic cases of deliberation because special emphasis was placed by the government having proceeded to the change of the title of Ministry of Education. Thus, the Ministry of Education and Religion was re-named to Ministry of Education, Lifelong Learning and Religion. Even though the deliberation on Lifelong Education was projected by the Mass Media, single carriers and individuals having been involved demonstrated a lack of interest generated by the citizens' society about the specific issue.

Based on the answers provided by the carriers and individuals involved in the procedure of deliberation, it seems that Lifelong Education is associated with the economic and political crisis. In terms of economic crisis, it is realized that the answers are concentrated on the association between Lifelong Education and functional knowledge acquisition corresponding to the labor market needs, taking into consideration the fluid and insecure state as this is formed within the framework of the capitalist system.

Individuals seem to have been familiarized with the flexible forms of labor (Sennet, 2007; 2010) and the fact that the professional roles will be continuously changing and individuals will be addressing the carriers to acquire knowledge has been accepted. The necessity of specialization and certification by promoting the professional associations towards the procedure of educating unemployed or training their members, related to the readjustment of professional roles as well as the professional associations' interest in regulating and monitoring the educational procedure is underlined by the carriers involved in the procedure of deliberation.

The fact that women feel the threat generated by the fluid economic and political situation, after having acquired a higher educational capital over the past decade and through the creation of the conditions that reduced inequality, is very interesting. The loss of labor positions is possibly interpreted as the comeback to traditional roles in which case policies on equality in terms of gender are cancelled. 
Individuals of higher educational capital are indirectly opposed to a system in which knowledge is standardized, formed into functional specialization by refuting the systematic study of scientific fields cancelling the research and humanistic content of science. It is observed that without overlooking the necessity of integrating individuals into professional spaces, the necessity of another content of knowledge is also pinpointed.

A sign of the political crisis in Greece is that the individuals and carriers have no confidence to the state services concerning the implementation of Lifelong Education. Besides, even Municipalities or Communities considered as decentralized political structures, are confronted with reservation. On the contrary, Non Governmental Organizations (NGO) and private carriers have gained both the carriers and individuals' positive opinion.

What is common both in carriers and individuals is the identification of the necessity for Lifelong Education admitting that the typical education pattern starting from elementary to high school and from high school to university or postgraduate studies is old. On the contrary, the new educational model is based on short-term educational or training patterns.

All in all, it is realized that the principle of deliberation on educational issues functioned typically although the utilization or not of the carriers or individuals' suggestions was not published. Thus, a democratic, innovative procedure being integrated into the direct citizens' deliberation and embodying a new view about democracy (Habermas, 1989) and its possibilities in the postmodern societies did not function.

Deliberation throughout 2009-2012 has been associated with a new policy of elevating and projecting the relationship between the citizens' society with the legalized form of authority, the government. It is important that during an economic crisis period, new policy issues are pushed forward in which the limits of forming laws and political standpoints are redefined. The political system is being tested and deliberation is perhaps an attempt to get out of the crisis, not only the economic one. Perhaps, it is about the opening of a broader dialogue concerning the rejection of ineffective policies and promotion of new political forms.

\section{References}

Al-Hawamdeh, S., \& Hart, T. L. (2002). Information and Knowledge Society. Singapore: McGraw Hill.

Bandin, L. (1977). L' analyse de contenu. Paris: PUF.

Bauman, Z. (2007). Liquid Times: Living in an Age of Uncertainty. London: Rutledge.

Bauman, Z. (2011). Culture in a Liquid Modern World. London: Rutledge.

Berelson, B. (1971). Content Analysis in Communication Research. New York: The Free Press.

Bourdieu, P., \& Boltanski, L. (1981). The Educational System and the Economy: Titles and jobs. In Ch.c. Lemmert (ed.), French Sociology. Rupture and Renewal Since 1968 (pp. 141-151). New York: Columbia University Press. 


\section{Macrothink}

International Research in Education

ISSN 2327-5499

2013, Vol. 1, No. 1

Carnoy, M. (1985). The Political Economy of Education. International Social Science Journal, XXXII(2), 157-158.

Carnoy, M., \& Castells, M. (1995). Sustainable Flexibility: A Prospective Study on Work, Family and Society in the Information Age. Stanford: University of Stanford-Berkeley.

Creswell, J. (2008). Research Design: Qualitative, Quantitative, and Mixed Methods Approaches. London: Rutledge.

Dale, R. (1982). Education and the Capitalist State: Contributions and Contradictions. In M. Apple (ed.), Cultural and Economic Reproduction in Education: Essays on Class, Ideology and the State (pp. 130-133). Boston: Rutledge \& Kegan Paul.

Dehmel, A. (2006). Making a European area o lifelong learning a reality? Some critical reflections on the European Union's lifelong learning policies. Journal of Comparative Education, 42(1), 49-62. http://dx.doi.org/10.1080/03050060500515744

De Sola Pool, I. (1959). Content analysis. Urbana, Ill: University of Illinois Press.

$\begin{array}{llll}\text { Europa. } & \text { (n.d.). } & \text { Retrieved }\end{array}$ http:Europa.eu.int/eur-lex/pri/en/oj/dat/2002/c_163/c_16320020709en00010003.pdf

$\begin{array}{llll}\text { European } & \text { Commission. } & \text { (2009). } & \text { Retrieved }\end{array}$ http://europa.eu.int/comm/education/policies/2010/doc/progressreport 06 en.pdf

Giroux, H., \& McLaren, M. (1989). Critical Pedagogy. The State and Cultural Straggle. State New York: University of New York Press.

Grawitz, M. (1981). Methodes des sciences sociales. Paris: Dalloz.

Habermas, J. (1989). The Structural Transformation of the Public Sphere: An Inquiry into a Category of Bourgeois Society (Studies in Contemporary German Social Thought). Massachusetts: Institute of technology.

Halsey, A., Lauder, H., Brown, P., \& Stuart-Wells, A. (1997). Education: Culture, Economy, and Society. Oxford: Oxford University Press.

Hirata, H. (1988). Workers' response to job loss: Female and male industrial workers in Brazil. UK: Institute of Development Studies at the University of Sussex, Brighton.

Holsti, O. R. (1969). Content Analysis for the Social Sciences and the Humanities. Mass: Addison-Wesley.

Jarvis, P. (2010). Adult Education and Lifelong Learning: Theory and Practice. London; New York: Routledge.

Krippendorff, K. (2012). Content Analysis: An Introduction to Its Methodology. London: SAGE.

Lagarde, J. D. (1983). Initiation a l'Analyse des Donees. Paris: Dunod. 


\section{Macrothink}

International Research in Education

ISSN 2327-5499

2013, Vol. 1, No. 1

Lasswell, H. D., \& De Sola Pool, I. (1952). The comparative study of symbols. Stanford: Stanford University Press.

Lasswell, H. D., \& Leites, N. (1965). The Language of Politics: Studies in Quantitative Semantics. New York: MIT Press.

Leetaru, K. (2011). Data Mining Methods for the Content Analyst: An Introduction to the Computational Analysis of Content. London: Rutledge.

Lewis, J. (2002). National Interests: Coreper. In J. Peterson, \& M. Shackleton (eds), The Institutions of the European Union. Oxford :Oxford University Press.

McMahon, J. (1995a). Education and Culture in European Community Law. London: The Athlone Press.

McMahon, J. (1995b). Covert action? Education, social policy and law in the European Union. Journal of Education Policy, 18(5), 551-562.

Moscovici, S. (1970). La psychanalyse, son image et son public. Paris: PUF.

Mucchieli, R. (1988). L'analyse de contenu des documents et des communications. Paris: Les Editions ESF.

Palmquist, M. (1990). The lexicon of the classroom: language and learning in writing classrooms. (Unpublished Doctoral Dissertation). Carnegie Mellon University.

Preece, J. (2011). Lifelong Learning and Development: A Southern Perspective (Continuum Studies in Educational Research). London: Rutledge.

Raju, P. (2010). Knowledge Society: Opportunity and Challenges. Delhi, 2010.

Riddell, S., Markowitsch, J., \& Weedon, E. (2012). Lifelong Learning in Europe: Equity and Efficiency in the Balance. Great Britain: Policy Press. http://dx.doi.org/10.1332/policypress/9781447300137.001.0001

Schreier, M. (2012). Qualitative Content Analysis in Practice. London: Rutledge.

Schultz, T. (1960). Capital Formation by Education. Journal of Political Economy, 68, 571-584. http://dx.doi.org/10.1086/258393

Schultz, T. (1971). Investment in Human Capital: The Role of Education. New York: Free Press.

Sennet, R. (2007). The Culture of the New Capitalism. London: Sennet.

Sennet, R. (2010). The Craftsman. London: Sennet.

Sofer, C. (2004). Human Capital over the Life Cycle: A European Perspective. Northampton, MA: Edward Elgar Publishing

Veron, E. (1981). La construction des evenements. Paris: Les Editions de Minuit.

Weber, R. P. (1990). Basic Content Analysis (2nd ed.). Newbury Park, CA: Sage. 


\section{Macrothink

Zito, A. (2001). Epistemic communities, collective entrepreneurship and European Integration. Journal of European Public Policy, 8(4), 585-603. http://dx.doi.org/10.1080/13501760110064401

\section{Copyright Disclaimer}

Copyright reserved by the authors.

This article is an open-access article distributed under the terms and conditions of the Creative Commons Attribution license (http://creativecommons.org/licenses/by/3.0/). 